\title{
Performance analysis of a spring-tooth drum pickup of straw baler via coupling simulation
}

\author{
Qingqing Wang ${ }^{1,2}$, Yongcheng Jiang ${ }^{3}$, Lianhao Li ${ }^{4}$, Junwei Qin ${ }^{1}$, Liqing Chen ${ }^{1,2^{*}}$ \\ (1. School of Engineering, Anhui Agricultural University, Hefei 230036, China; \\ 2. Laboratory of Engineering of Intelligent Agricultural Machinery Equipment, Anhui Province, Hefei 230036, China; \\ 3. School of Mechanical Engineering, Jiamusi University, Jiamusi 154007, Heilongjiang, China; \\ 4. School of Mechanical and Electrical Engineering, Henan Agricultural University, Zhengzhou 450002, China)
}

\begin{abstract}
In order to solve the problem of poor working performance due to incidental picking-up loss of a spring-tooth drum pickup, the coupling analysis approach of Automated Dynamic Analysis of Mechanical Systems (ADAMS) and Discrete Element Method (DEM) was proposed to reveal its motion characteristics. The coupled ADAMS-DEM method was used to construct the pickup simulation model with rice straw as the object. The validation tests were carried out in the field with different operating forward speeds and straw coverages. The results showed that when the baler worked with a rake, the straw loss rate tended to rise with the increase of the operating speed and the straw coverage. Tests results indicated periodic peaks and valleys of the forces between the rollers and the track chute, which could increase the wear of the track chute. In addition, the movement and variation of the straw and the distribution of different straw lengths after picking up were analyzed. The research results can provide a reference for the design and optimization of a pickup in the later period.
\end{abstract}

Keywords: ADAMS-DEM coupling, loss rate, pickup, straw coverage, straw baler

DOI: $10.25165 / j . i j a b e .20211404 .6576$

Citation: Wang Q Q, Jiang Y C, Li L H, Qin J W, Chen L Q. Performance analysis of a spring-tooth drum pickup of straw baler via coupling simulation. Int J Agric \& Biol Eng, 2021; 14(4): 159-165.

\section{Introduction}

Straw baling and collection with a baler after crop harvest, which is then processed into an energy source, has become the mainstream in straw treatment. The amount of straw produced globally is about 200 million $\mathrm{t} / \mathrm{year}^{[1,2]}$, and the traditional disposal involved abandonment or incineration, which not only wasted a large amount of biomass resource but also caused serious environmental pollution ${ }^{[3,4]}$. With the massive consumption of energy and the promotion of a sustainable development strategy, straw recycling has nowadays become the main approach for straw disposal. Using rapidly developing technology, the recycled straw is processed and can be used as biomass fuel, animal feed, organic fertilizer or for paper and fiberboard making ${ }^{[5-9]}$, especially in the building industry, where straw has become one of the most favorite building materials for sustainable development ${ }^{[5,10]}$. This not only opens up a new way in old straw disposal, but, to a certain extent, alleviates resource scarcity and environmental pollution. In the whole process, balers act as an important tool for field recovery, and currently, the balers on the market can be divided into square ones and round ones, according to their baling methods ${ }^{[11]}$.

\section{Received date: 2021-03-08 Accepted date: 2021-06-25}

Biographies: Qingqing Wang, PhD candidate, research interest: modern agricultural equipment design and computer measurement and control technology research, Email: wqq6322@163.com; Yongcheng Jiang, PhD, research interest: intelligent detection and control technology research, Email: jiangyongcheng@126.com; Lianhao Li, PhD, research interest: mechanical design theory research, Email: lianhao8002@126.com; Junwei Qin, PhD, research interest: modern agricultural equipment design, Email: i13856035016@163.com.

*Corresponding author: Liqing Chen, $\mathrm{PhD}$, Professor, research interest: intelligent agricultural equipment design and theory research. College of Engineering, Anhui Agricultural University, Hefei 230036, China. Tel: +86-13966658997, Email: lqchen@ahau.edu.cn.
As a key component common to both round and square balers, the pickup performance directly affects the quality of baling operation. For a baler pickup, a series of studies have been conducted by domestic and foreign scholars. Tang et al. ${ }^{[1]}$ conducted a theoretical analysis on the motion process of the spring teeth and determined the working parameters of the picking-up device, using a graphical method in the design of the baler. Ding et al. ${ }^{[12]}$ abstracted the mechanical structure of the picking-up device into a mechanical model, and deduced a set of theoretical design methods suitable for the picking-up device by means of mathematical analysis. Yu et al. ${ }^{[13,14]}$ explored the effects of drum speed and forward speed of a pickup and moisture content of forage on the picking-up performance using bench tests. In addition, some scholars optimized the key components of the picking-up device with ADAMS, and the optimized parts were verified by a bench test ${ }^{[15,16]}$. It can thus be seen that although a series of studies have been conducted on the pickup, most of them focused on the optimization of the pickup performance through theoretical analyses or bench tests.

Although quite a few scholars have made certain progress in the research of picking-up devices, there are still some limitations: 1) The studies were more concerned about an original stubble field, and straw coverages were rather incomprehensive. However, with the rapid development of mechanization, straw balers are mostly used together with rakes, thus different from the condition of an original stubble land; 2) The research methods were relatively singular and much more attention was paid to the optimization of the operation performance of the pickup. There are few reports on the research into the motion state and change pattern of straw during the operation of a pickup.

In recent years, as the computer technology develops rapidly, the discrete element method has been widely used, especially in the field of agriculture ${ }^{[17-20]}$. The feasibility and effectiveness of such a research method, in which the discrete element method is 
employed to simulate crop straw, has already been demonstrated. For example, Zhao et al. ${ }^{[21]}$ used discrete element simulation to construct a straw model, followed by a simulation analysis on the feeding device of the baler. Wang et al. ${ }^{[22]}$ studied the interaction between the cutter and the straw by using the discrete element method. In addition, Lei et al. ${ }^{[23]}$ used computational fluid dynamics (CFD)-DEM coupling method to simulate the motion state of wheat particles under airflow blowing. Ma et al. ${ }^{[24]}$ applied ADAMS-DEM coupling simulation method to study the motion process of agricultural particles in a variable amplitude dynamic sieve. Su et al. ${ }^{[25]}$ conducted a study on the impact energy absorption and attachment of a space robot bionic buffer system through the ADAMS-DEM coupling simulation. The above results show that DEM software has been widely used in agricultural research, and coupling simulation tests facilitated with DEM and other software have been verified in related fields.

The main work of this study is as follows: Section 2 describes the basis of establishing the model of straw mulching in the field, the establishment of the coupling simulation model of the pickup and the test method, which verifies the accuracy of the model.
Section 3 mainly analyzes the movement characteristics of straw, the change law of picking loss rate and the force on the track slot, and puts forward the corresponding optimization scheme. Section 4 draws the conclusions of this study. The research method and results can provide a reference for the design and optimization of high-efficiency, high-speed baler pickups.

\section{Materials and methods}

\subsection{Working principle of a pickup and operation analysis}

Figure 1 shows the supporting equipment for baler operation. In order to improve the efficiency of the baler operation, the straw is gathered by a rake in the field before the operation to form windrows suitable for baling, a practice that has become a dominant treatment. According to the survey into the market and baler manufacturers, it has been found that in the actual field operation, the rotating speed of a pickup is relatively fixed, and its forward speed can be adjusted to straw quantity in the field. The traction speed of the mainstream balers in the field is generally $4-6 \mathrm{~km} / \mathrm{h}$, and the working speed of a pickup is $287 \mathrm{r} / \mathrm{min}$.

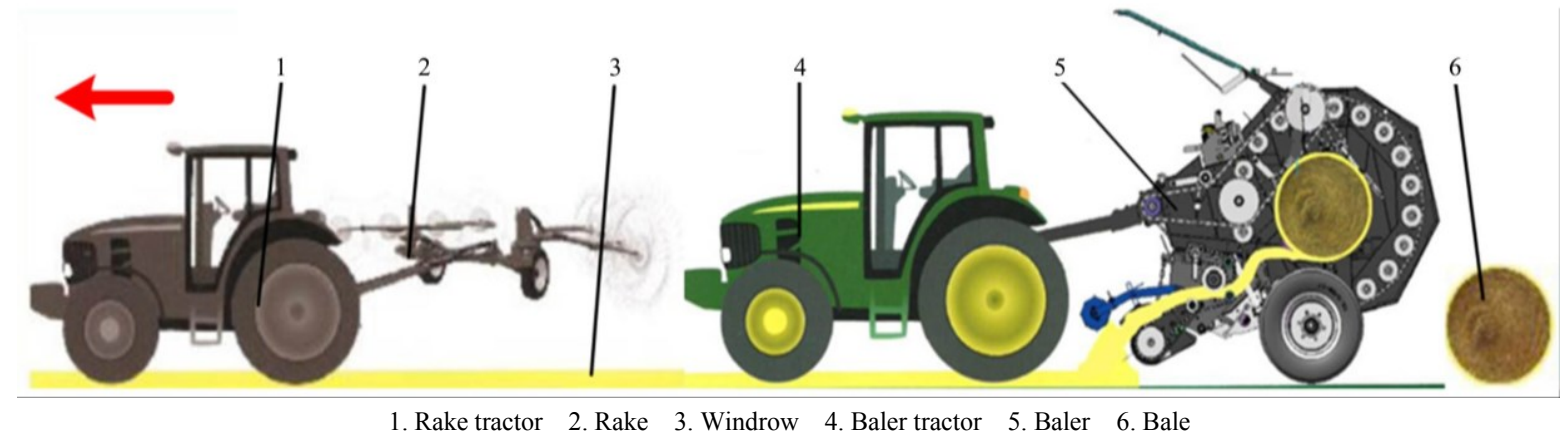

Figure 1 Supporting tools for baling operation

As an important component in the baling operation, a spring-tooth drum pickup is mainly used to pick up and lift the straw scattered in the field and transport it to the feeding mechanism. Its structure is shown in Figure 2, in which $S_{0}$ to $S_{8}$ represent the motion of the tooth tine at different moments, and the motion trajectory of the tooth tine is depicted by the blue line in Figure 2.

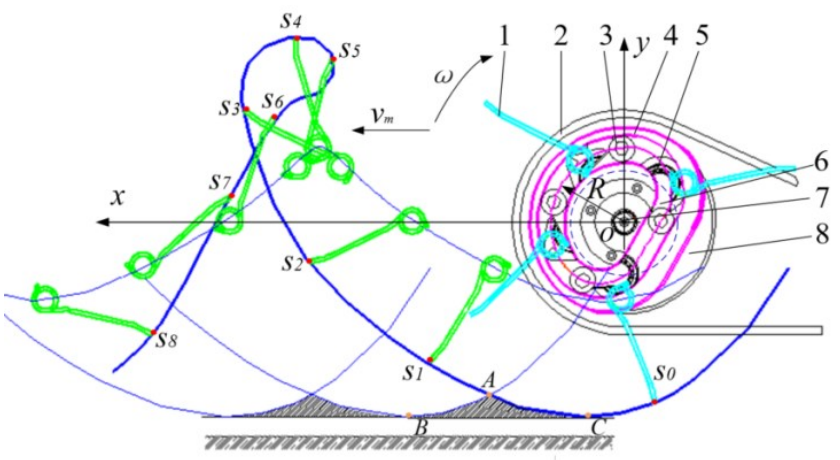

1. Spring tooth 2. Guard plate 3. Roller 4. Track chute plate 5. Spring tooth rod 6. Crank 7. Pickup shaft 8. Fixed plate

Note: $S_{0}$ to $S_{8}$ represent the motion of the tooth tine at different moments; $v_{m}$ is the forward speed, $\mathrm{m} / \mathrm{s} ; \omega$ is the rotating speed of the drum, $\mathrm{rad} / \mathrm{s}$; point $A$ is the intersection point of the trajectories of the two adjacent rows of spring-tooth tines, while $B$ and $C$ are the lowest points of the two adjacent tooth tins in the movement process.

Figure 2 Trajectory of spring tooths in pickup

It can be seen from Figure 2 that point $A$ is the intersection point of the trajectories of the two adjacent rows of spring-tooth tines, while $B$ and $C$ are the lowest points of the two adjacent tooth tins in the movement process. The closed shadow area $A B C$ in Figure 2 is the area that cannot be covered by the tines in the working process, which is called the picking-up leakage area, and the leakage area is thus calculated as follows ${ }^{[14]}$ :

Set the equation of the trajectory of spring-tooth tines as below:

$$
y=f(x)
$$

Then, the trajectory equation of the tines of adjacent spring teeth can be set accordingly:

$$
y_{0}=f\left(x-\frac{v_{m}}{Z \omega}\right)
$$

Thus, the leakage area $S$ is obtained as follows:

$$
\left\{\begin{array}{l}
S=\int_{X_{C}}^{X_{A}} y+\int_{X_{A}}^{X_{B}} y_{0}-\frac{v_{m} y_{C}}{Z \omega} \\
X_{B}=X_{C}-\frac{v_{m}}{Z \omega}
\end{array}\right.
$$

where, $v_{m}$ is the forward speed, $\mathrm{m} / \mathrm{s} ; Z$ is the number of tooth bars; $\omega$ is the rotating speed of the drum, $\mathrm{rad} / \mathrm{s} ; y_{0}$ is the vertical displacement of adjacent spring tooth tines, $\mathrm{m} ; X_{A}, X_{B}, X_{C}$ are the horizontal coordinate of points $A, B, C, \mathrm{~m} ; y_{c}$ is the vertical coordinate when the tooth tine is at the lowest point, $\mathrm{m}$.

\subsection{Establishment of discrete element straw coverage model}

In the experiment, rice straw was chosen as the research object. To improve the accuracy of the simulation, the amount and length of rice straw cover were measured after crushing and throwing by the harvester. A sampling frame of $1 \mathrm{~m} \times 1 \mathrm{~m}$ was used to randomly select three groups for measurement, and the mean value of straw coverage was $0.65 \mathrm{~kg} / \mathrm{m}^{2}$. The rice straws were divided 
into five different length intervals of $\leq 70 \mathrm{~mm},>70-150$ $\mathrm{mm},>150-230 \mathrm{~mm},>230-310 \mathrm{~mm}$, and $>310 \mathrm{~mm}$, respectively. The mass distribution of different straw length straws is shown in Figure 3. In the simulation, the above five interval lengths of rice straw were set to be $45 \mathrm{~mm}, 110 \mathrm{~mm}, 190 \mathrm{~mm}, 270 \mathrm{~mm}$, and $350 \mathrm{~mm}$, respectively.

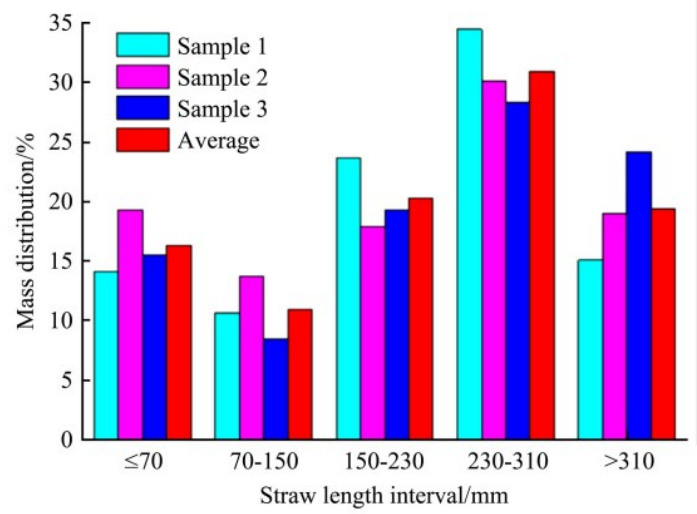

Figure 3 Mass distribution of the straw with different intervals lengths

Combined with the operating efficiency of the computer, the currently popular Hertz-Mindlin particle contact model was chosen. Its characteristic is that it can build particle models more quickly and accurately, which has been successfully applied in related studies ${ }^{[26,27]}$. The contact relationship of the particles is shown in Figure 4. The methodological calculation of the variables of interest is shown below. The general force and damping force are calculated as following equations:

$$
\begin{gathered}
F_{n}=\frac{4}{3} E^{k} \sqrt{R^{k}} \delta_{n}^{3 / 2} \\
F_{n}{ }^{t}=-2 \sqrt{\frac{5}{6}} \beta \sqrt{S_{n} m^{k}} v^{\text {rel }}
\end{gathered}
$$

where, $F_{n}$ is the general force, $\mathrm{N} ; F_{n}{ }^{t}$ is the damping force, $\mathrm{N} ; E^{k}$ is Young's modulus, GPa; $R^{k}$ is the equivalent radius, $\mathrm{m} ; \delta_{n}$ is the general overlap, $\mathrm{m} ; \beta$ is termed the angle of rolling resistance, $\left({ }^{\circ}\right) . S_{n}$ is general stiffness, $\mathrm{N} / \mathrm{m} ; m^{k}$ is the mass, $\mathrm{kg} ; v^{r e l}$ refers to the normal component of relative velocity between particles $i$ and $j, \mathrm{~m} / \mathrm{s}$.

Tangential force $F_{t}$ and tangential damping force $F_{t}^{t}$ are calculated as below:

$$
\begin{gathered}
F_{t}=-S_{t} \delta_{t} \\
F_{t}^{t}=-2 \sqrt{\frac{5}{6}} \beta \sqrt{S_{t} m^{k}} v_{t}^{r e l}
\end{gathered}
$$

where, $S_{t}$ is the tangential stiffness, $\mathrm{N} / \mathrm{m} ; \delta_{t}$ is the tangential overlap, $\mathrm{m} ; v_{t}^{r e l}$ is the tangential component of the relative velocity between particles $i$ and $j, \mathrm{~m} / \mathrm{s}$.

$$
S_{t}=8 G^{k} \sqrt{R^{k} \delta_{n}}
$$

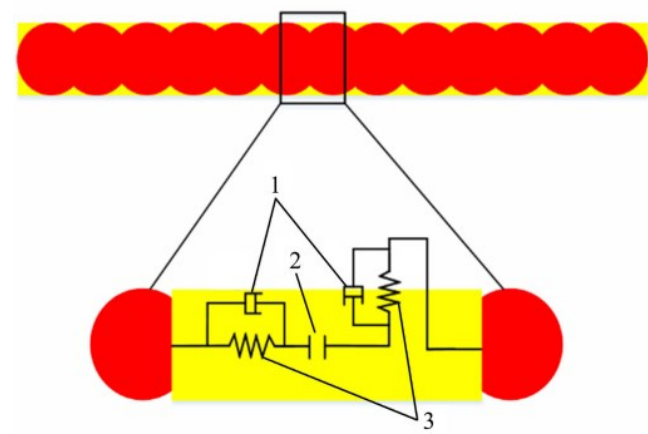

$\begin{array}{lll}\text { 1. Particle stiffness } & \text { 2. Damping } 3 \text {. Friction }\end{array}$

Figure 4 Straw particle model

\subsection{Establishment of pickup coupling model}

\subsubsection{Model establishment}

In order to reduce the complexity of the model and improve the simulation ability of the computer, CATIA software was used to build a simulation model of the pickup, which was saved in a .stp format. The structural parameters of the key components of the pickup were used in the simulation are listed in Table 1.

Table 1 Structural parameters of the spring-tooth drum pickup

\begin{tabular}{lc}
\hline \multicolumn{1}{c}{ Parameter } & Value \\
\hline Crank length/mm & 760 \\
Base radius/mm & 112 \\
Number of spring-tooth bars & 4 \\
Length of spring tooth/mm & 110 \\
Number of spring teeth & 24 \\
\hline
\end{tabular}

Before carrying out the simulation, the script file for the co-simulation topology of ADAMS and DEM needs to be configured so that the data transfer between ADAMS and DEM can be established. The versions of the software selected for this study were ADAMS2019 and DEM2018. Import the simplified pickup model into the two software respectively, and set up the reference Figure 5. The material property parameters and the parameters of mutual contact are referred to in the previous studies $^{[21,28,29]}$.

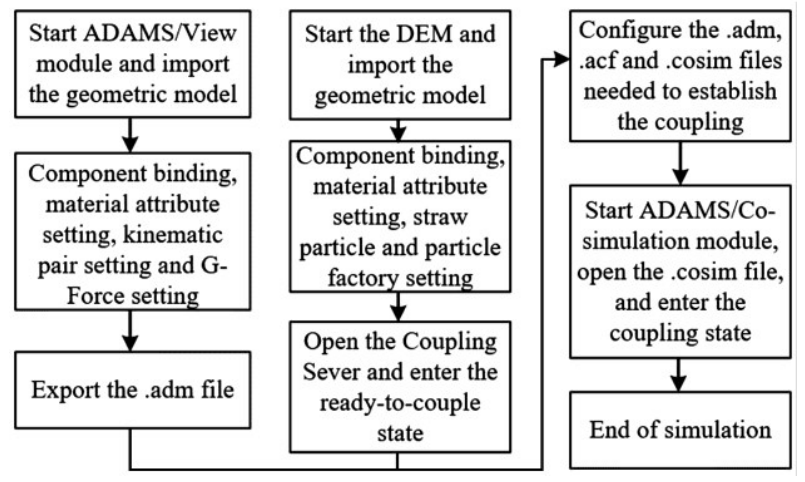

Figure 5 ADAMS-DEM coupling simulation process

As shown in Figure 6, the motion attributes of each component were set in ADAMS, with the rotating speed set to $287 \mathrm{r} / \mathrm{min}$. In addition, importing straw roller and the straw chamber into the DEM, and select the Hert-Mindlin no slipping model. The size of the soil trough model was set to $10000 \mathrm{~m}$ (Length) $\times 1500 \mathrm{~m}$ (Width) $\times 150 \mathrm{~mm}$ (Height), that of particle factory was set to 6000 $\mathrm{mm}$ (Length) $\times 860 \mathrm{~mm}$ (Width), and the straw coverage model was established with reference to actual measured values. The forward speed was set by the relative movement of the soil trough, and the total simulation time was set to $8 \mathrm{~s}$ so that the rice straw could be generated within $1.0 \mathrm{~s}$, and the pickup could start to move after 1.0 s. Figures 6 and 7 show the coupled model using ADAMS and DEM.

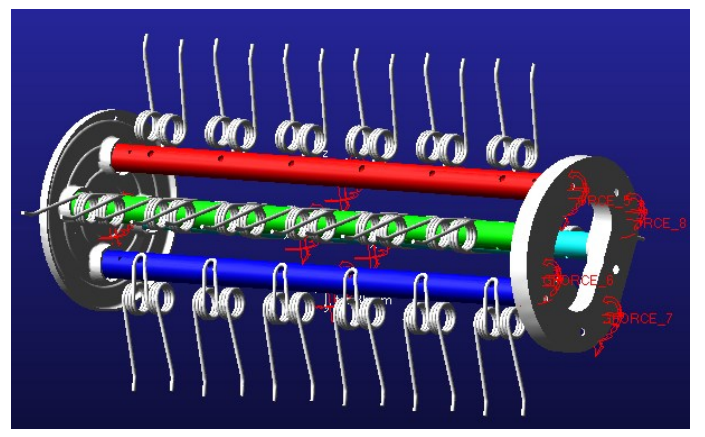

Figure 6 Dynamic setting of the pickup 


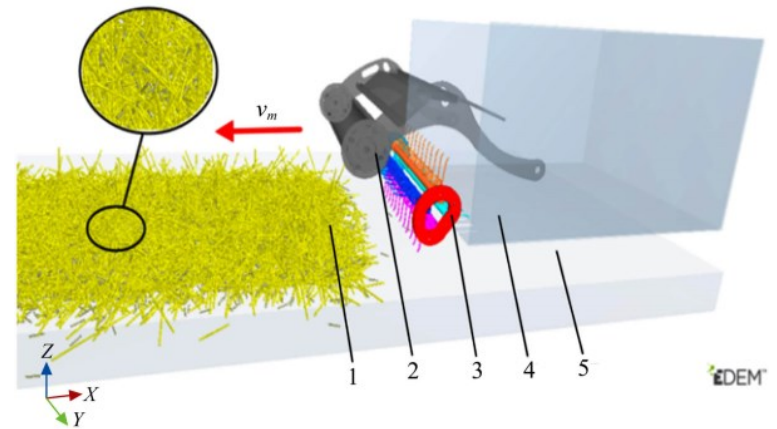

1. Straw-covering ground 2. Straw roller 3. Pickup mechanism 4. Straw chamber 5. Straw coverage bin

Figure 7 Establishment of the discrete element model for the straw pickup

\subsubsection{Design of the test scheme}

It can be seen from the previous analysis that the actual operating speed of a baler is mostly $4-6 \mathrm{~km} / \mathrm{h}$, and the operating width of a mainstream rake is about $6-8 \mathrm{~m}$. For the convenience of calculation, the operating speeds of $4 \mathrm{~km} / \mathrm{h}, 5 \mathrm{~km} / \mathrm{h}$, and $6 \mathrm{~km} / \mathrm{h}$ were selected for the simulation. The working width of the raking machine was set to $6 \mathrm{~m}$ and $8 \mathrm{~m}$, and the width of the straw strips formed after the operation was $1.2 \mathrm{~m}$ so that the amount of straw coverage was $3.25 \mathrm{~kg} / \mathrm{m}^{2}$ and $4.33 \mathrm{~kg} / \mathrm{m}^{2}$. Therefore, the straw coverage was selected to be $0.65 \mathrm{~kg} / \mathrm{m}^{2}, 3.25 \mathrm{~kg} / \mathrm{m}^{2}$ and $4.33 \mathrm{~kg} / \mathrm{m}^{2}$. After the tests, the straw loss rate was calculated with reference to the existing studies ${ }^{[15]}$.

\subsection{Simulation validation}

The field verification test was conducted in Datong Town, Tianchang City, Anhui Province, China in November 2020, as shown in Figure 8. The test field was a paddy field harvested by a combined machine. In the tests, the tractor was a Zoomlion 1204 model and the straw baler was 9YY-1250. The forward speed was set at $5 \mathrm{~km} / \mathrm{h}$ and the straw coverage was $0.65 \mathrm{~kg} / \mathrm{m}^{2}$, $3.25 \mathrm{~kg} / \mathrm{m}^{2}$, and $4.33 \mathrm{~kg} / \mathrm{m}^{2}$ for three conditions. The validation tests were conducted in the field and the simulation tests were carried out using a computer. The results obtained are shown in Figure 9.

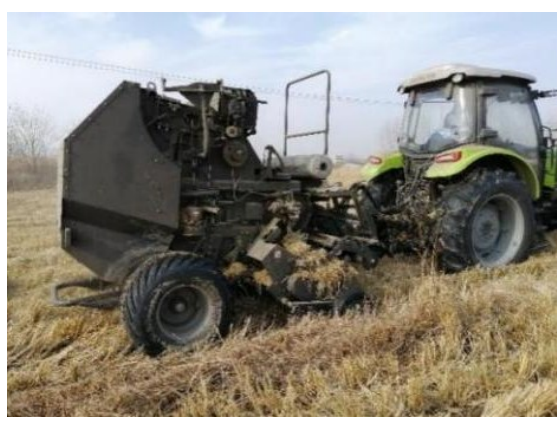

Figure 8 Field validation test

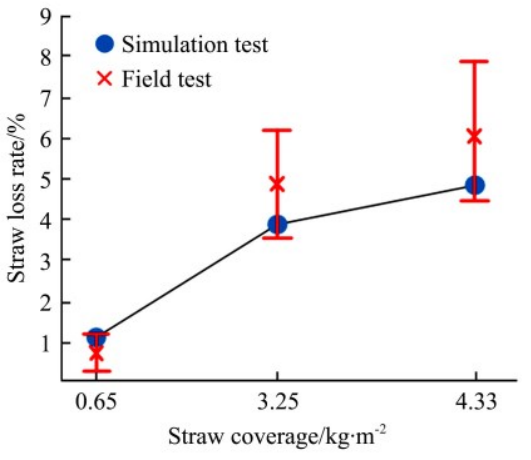

Figure 9 Straw loss rate under different coverages
A generally consistent trend was observed in the results, with relative error values within $3.04 \%$ for the straw loss rate under different conditions. The sources of errors are mainly the parameter errors and random errors during the test, which are within the allowed range and verify the accuracy of the coupling simulation.

\section{Results and discussion}

\subsection{Analysis of the picking-up motion process}

Figure 10 shows the changes of straw motion state at different times under the action of the pickup. In this study, such a small area of straw directly in front of the pickup as the red one marked in Figure 10 was randomly selected, and this area was defined as a "straw block". In order to clearly observe the process of "straw block" change, the pickup is shown in a side sectional view, with the straw roller concealed. From Figure 10, it can be seen that under the action of the pickup, the "straw block" mainly goes through four states: squeezing, towing, picking, and collecting. The states and motion characteristics of the straw at different moments are as follows:

1) Initial state: the "straw block" is comparatively loose, and the upper surface of the straw coverage layer is rather flat $(2.0 \mathrm{~s})$.

2) Squeezing state: The "straw block" is deformed, and the upper straw begins to slip forward (2.1 s).

3) Towing state: As the pickup continues to advance, the "straw block" becomes loose and disordered. The increase of straw slippage in the upper layer results in the superimposition, forming a "straw pile", which tends to move upward under the drag of the straw that has been picked up. At this stage, the spring teeth have not been in contact with straw in the "straw block" $(2.2 \mathrm{~s})$.

4) Pick-up state: As the pickup moves forward, the "straw pile" and the spring teeth begin to interact, and the "straw pile" gradually spreads out under the action of the pickup, forming a "straw flow", which continues to move backward under the action of the teeth (2.3 s).

5) Collection state: Under the action of the teeth, the "straw flow" gradually disperses and is thrown into the straw chamber at the rear $(2.5 \mathrm{~s})$.

6) End state: The pickup completes the picking up of the "straw block", which then falls into the straw chamber $(2.8 \mathrm{~s})$.

Through the above analysis of the whole motion process of the "straw block" under the action of the teeth, it can be concluded that the "straw block" mainly undergoes the state changes of squeezing, towing, picking, and collecting, among which towing and picking are the key ones to determine whether the straw can be successfully picked up. The interaction between the straw and the pickup can be increased by adjusting the structure of the straw pressing roller so that the picking-up rate can be improved.

\subsection{Analysis of pickup operational performance}

\subsubsection{Analysis of picking-up loss rate}

Under the conditions of different forward speeds and straw coverage, which obtain the straw loss rate of results are shown in Figure 11. When the straw coverage was $0.65 \mathrm{~kg} / \mathrm{m}^{2}$, the change in straw loss rate was relatively small as the machine forward speed increased, indicating that, with a small straw coverage and at an allowable forward speed, the picking-up effect on straw would be much desirable. It can be observed in Figure 11 that when the straw coverage was set to $3.25 \mathrm{~kg} / \mathrm{m}^{2}$ and $4.33 \mathrm{~kg} / \mathrm{m}^{2}$, the picking-up loss rate gradually went up with the increase of the forward speed. That may be due to the fact that the frequency of 
the ring buckle formed by the rotation of the teeth in the process of acceleration remained unchanged, which led to the enlargement of the leakage area, thus increasing the picking-up loss rate. In addition, it was also possible that the enlargement of the straw coverage might increase the straw accumulation in the feeding area formed by the pickup and the pressure roller, while tooth movement was unable to convey the straw backward in time, thus
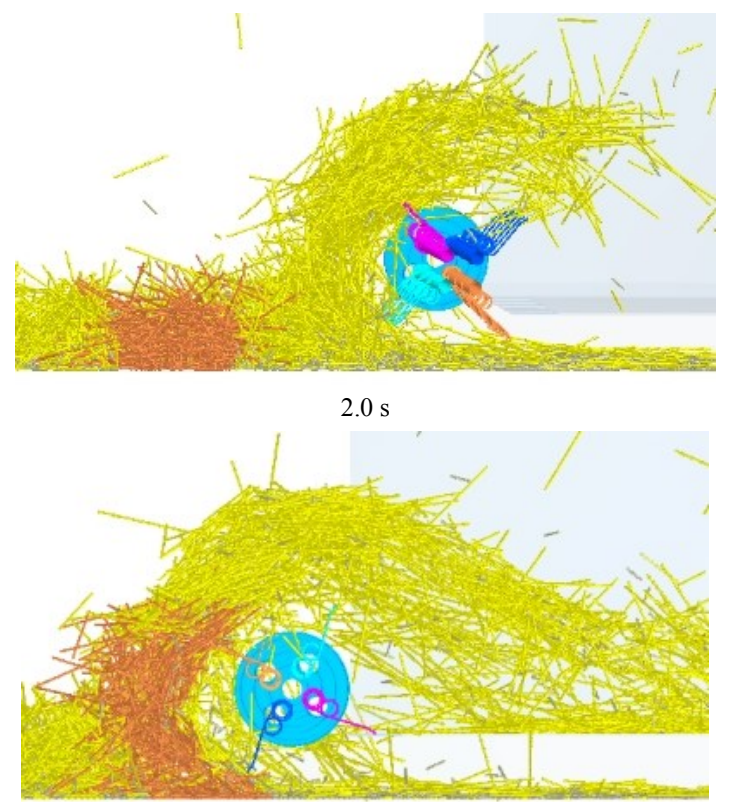

$2.2 \mathrm{~s}$

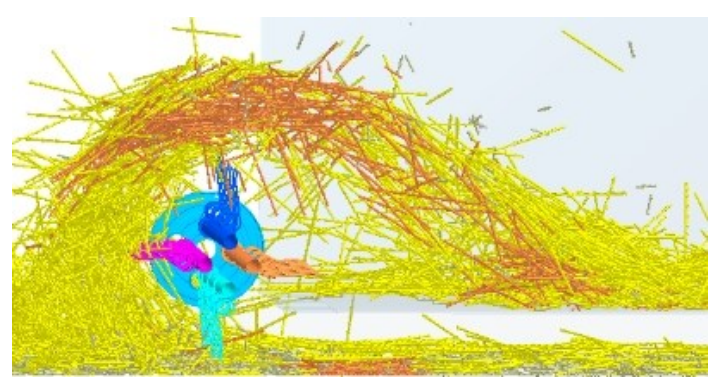

$2.5 \mathrm{~s}$ resulting in the overflowing from both sides of the feeding area or the continuous piling-up in front of the machine. Consequently, the straw was moved to the top of the roller, which may lead to congestion in picking up, increasing the loss rate and impairing the working efficiency. It can also be observed from Figure 10 that the accumulation of straw in front of the pickup was gradually increasing, as it continued its advance.
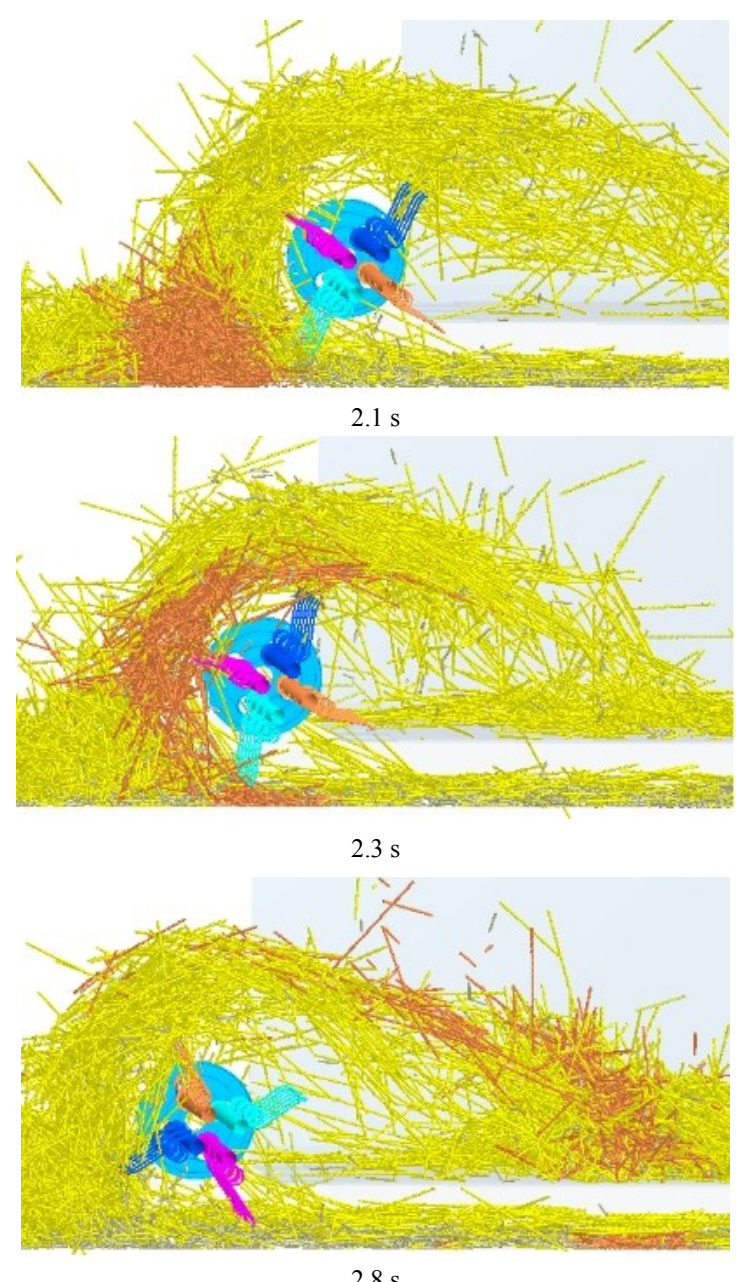

$2.8 \mathrm{~s}$

Figure 10 Movement changes of "straw block" at different times

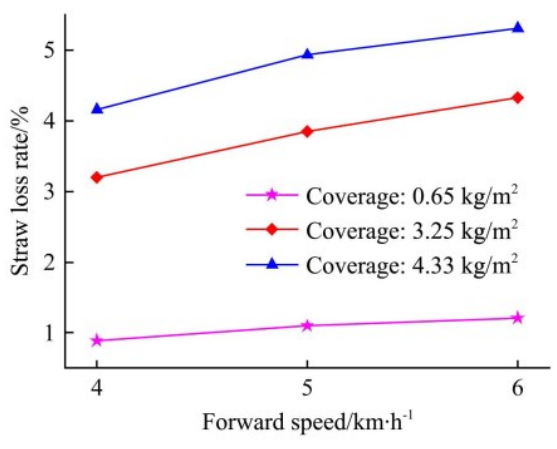

Figure 11 Test results of pickup loss rate

\subsubsection{Length distribution in straw loss}

To further analyze the mass changes of different lengths of straw after the operation. The mass distribution of straw lengths remaining was calculated after the operation at different forward speeds by putting the straw cover at $3.25 \mathrm{~kg} / \mathrm{m}^{2}$ and $4.33 \mathrm{~kg} / \mathrm{m}^{2}$, and the results are shown in Figure 12. Since straws $\leq 70 \mathrm{~mm}$ in length are not taken into account in the loss rate calculation, the straws in this interval are not analyzed in the straw length mass distribution.
It can be seen from Figure 12 that the trends of the mass distribution of straw in different length intervals were, by and large, the same for different operating speeds and straw coverages, which were closely related to the mass distribution of original straw lengths. However, as the forward speed gradually went up, the amplitude variation of each working condition gradually increased, too. It is obvious that for the straw in the length of 70-150 mm, with an increase in forward speed, the leakage rate gradually reduced, much close to the distribution ratio before operation. This may be due to the increase of the operating speed, the accumulation of straw in front of the pickup gradually built up under the condition of the same straw coverage, causing an obvious squeezing effect between straw and a higher accumulation density in front. For the straw in shorter lengths, a high packing density could reduce the probability of being missed by the "screening" action of the teeth, which was more conducive to being picked up.

In Figure 12, when comparing the straw length-mass distribution after two different coverage operations, it can be found that the coverage of $4.33 \mathrm{~kg} / \mathrm{m}^{2}$ had a greater variation than that of $3.25 \mathrm{~kg} / \mathrm{m}^{2}$ under the same forward speed, and the straw mass distributions in different length intervals were much closer than 
those before the operation. For the straw in a length greater than $150 \mathrm{~mm}$, no obvious pattern of changes was founded in the operating speed and the straw coverage when it came to the leakage of the straw in different interval lengths.

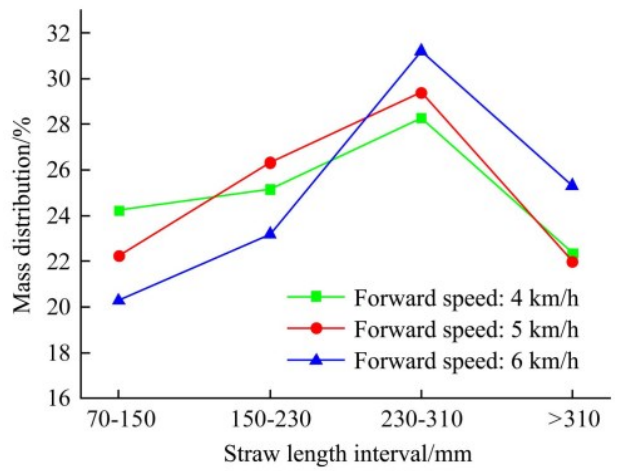

a. Straw coverage $3.25 \mathrm{~kg} / \mathrm{m}^{2}$

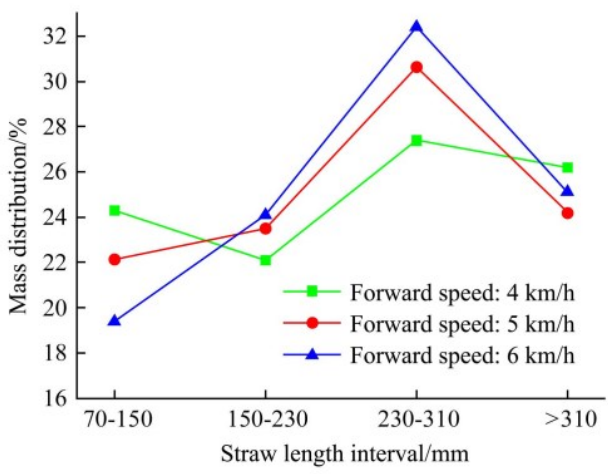

b. Straw coverage $4.33 \mathrm{~kg} / \mathrm{m}^{2}$

Figure 12 Distribution of straw length after picking-up

\subsection{Mechanical analysis of pickup motion}

In order to observe the force change between the roller and the track chute under different straw coverages, the force change between "Roller 1" and the track chute under different straw coverage conditions were selected in the post-processing of ADAMS, and the result is shown in Figure 13.

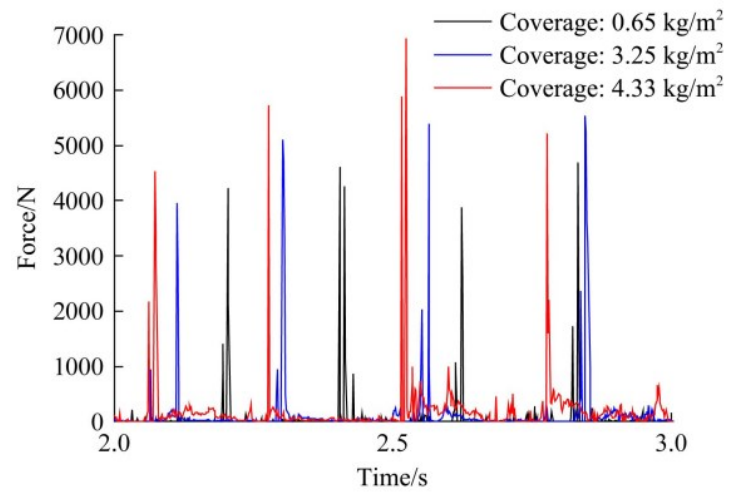

Figure 13 Periodic peaks of forces between rollers and track chute under different coverages

From Figure 13, it can be seen that under the conditions of constant forward speed and different straw coverages, the acting force between the roller and the track chute changed periodically, with intermittent peaks and valleys generated. On the whole, the force tended to rise with the increase of the straw coverage. The maximum acting force between the roller and the track chute was about $4600 \mathrm{~N}, 5500 \mathrm{~N}$, and $7000 \mathrm{~N}$ respectively under the straw coverages of $0.65 \mathrm{~kg} / \mathrm{m}^{2}, 3.25 \mathrm{~kg} / \mathrm{m}^{2}$, and $4.33 \mathrm{~kg} / \mathrm{m}^{2}$. Except for the peak value, the force between the roller and the track chute was slightly but obviously higher than that under other coverage conditions, in which the force in most periods was less than $500 \mathrm{~N}$, and showed a gradual growth with the increase of speed.

Through the above analysis, it can be found that during the normal operation of the pickup, the interaction between the roller and the track chute would produce a large impact in the local range of the track chute, which would aggravate the wear of the chute, thus impairing picking-up efficiency and service life.

\section{Conclusions}

1) In this study, the accuracy of the pickup simulation model based on the ADAMS-DEM coupling method was verified, the changing pattern of straw motion was analyzed, which can provide a reference for the performance improvement and structure optimization of pickups in the future.

2) When the pickup was used in cooperation with the rake, the picking loss rate tends to increase gradually as the operating speed and the amount of straw mulch increased.

3) The magnitude and variation pattern of the force between the track chute and the roller were predicted, which may provide a reference basis for subsequent optimization design of track chutes.

\section{Acknowledgements}

The authors acknowledge that this work was financially supported by the Collaborative Innovation Project of Anhui Colleges and Universities (Grant No. GXXT-2019-036), Anhui University Cooperation Collaborative Research Project (Grant No. GXXT-2020-011), and Graduate Student Entrepreneurship Fund Program (Grant No. 2020ysj-71).

\section{[References]}

[1] Tang Z, Li Y M, Cheng C. Development of multi-functional combine harvester with grain harvesting and straw baling. Spanish J. Agric. Res. 2017; 15(1): e0202. doi: 10.5424/sjar/2017151-10175.

[2] Zhou D Y, Li M, Li Y, Qi J T, Liu K, Xu C, et al. Detection of ground straw coverage under conservation tillage based on deep learning. Computers and Electronics in Agriculture, 2020; 172: 105369. doi: 10.1016/j.compag.2020.105369.

[3] Redcay S, Koirala A, Liu J D. Effects of roll and flail conditioning systems on mowing and baling of Miscanthus $\times$ giganteus feedstock. Biosystems Engineering, 2018; 172: 134-143.

[4] Huang X, Wang W W, Li Z D, Wang Q Q, Zhu C X, Chen L Q. Design method and experiment of machinery for combined application of seed, fertilizer and herbicide. Int J Agric \& Biol Eng, 2019; 12(4): 63-71.

[5] Cornaro C, Zanella V, Robazza P, Belloni E, Buratti C. An innovative straw bale wall package for sustainable buildings: experimental characterization, energy and environmental performance assessment. Energy \& Buildings, 2020; 208: 109636. doi: 10.1016/j.enbuild.2019. 109636

[6] Hu Y H, Wang H, He S P. Adaptive tracking control of an electronic throttle valve based on recursive terminal sliding mode. IEEE Transactions on Vehicular Technology, 2021; 70(1): 251-262.

[7] Zhang J, Wang H, Zheng J C. Adaptive sliding mode-based lateral stability control of steer-by-wire vehicles with experimental validations. IEEE Transactions on Vehicular Technology, 2020; 69(9): 9589-9600.

[8] Chen L, Wang H, Huang Y Z, Ping Z W, Yu M, Zheng X F, et al. Robust hierarchical sliding mode control of a two-wheeled self-balancing vehicle using perturbation estimation. Mechanical Systems and Signal Processing, 2020; 139: 106584. doi: 10.1016/j.ymssp.2019.106584.

[9] Espinosa E, Rol F, Bras J, Rodriguez A. Production of lignocellulose nanofibers from wheat straw by different fibrillation methods. Comparison of its viability in cardboard recycling process. Journal of Cleaner Production, 2019; 239: 118083. doi: 10.1016/j.jclepro.2019. 118083.

[10] Koh C H A, Kraniotis D. A review of material properties and performance of straw bale as building material. Construction and Building Materials, 2020; 259: 120385. doi: 10.1016/j.conbuildmat.2020. 
120385

[11] Pari L, Suardi A, Santangelo E, García-Galindo D, Scarfone A, Alfano V. Current and innovative technologies for pruning harvesting: A review. Biomass and Bioenergy, 2017; 107: 398-410.

[12] Ding H Q, Yu Z H, Liu W F, Li L, Deng W G. Theory analysis on kinematics characteristics of spring - finger cylinder pickup device. Journal of Agricultural Mechanization Research, 2015; 37(10): 76-78, 82.

[13] Yu Z H, Wang W M, Morigenbilige, Liu W F, Li L, Cui H M. Experiment on performance of spring-finger cylinder pickup collector. Transactions of the CSAM, 2017; 48(3): 106-112. (in Chinese)

[14] $\mathrm{Yu} \mathrm{Z} \mathrm{H}$, Huai S C, Wang W M. Leakage rate and optimization of working parameters for cylinder pickup collector based on spring-finger trajectory. Transactions of the CSAE, 2018; 34(4): 37-43. (in Chinese)

[15] Wang G Q, Yu Q, Bu Y L, Yu D N, Wang C M. Design of pickup baler and dynamic simulation of pickup roller. Transactions of the CSAM, 2001; 32(5): 59-61, 68. (in Chinese)

[16] Wang W M, Wang C G. Parameter analysis and simulation of spring-finger cylinder pickup collector. Transactions of the CSAM, 2012; 43(10): 82-89. (in Chinese)

[17] Wang Q Q, Li Z D, Wang W W, Zhang C L, Chen L Q, Wan L. Multi-objective optimization design of wheat centralized seed feeding device based on particle swarm optimization (PSO) algorithm. Int J Agric \& Biol Eng, 2020; 13(6): 76-84.

[18] Liu Z D, Wang Q J, Li H W, He J, Lu C Y, Yu C C. Fertilizer injecting route analysis and test for air-blowing seed-fertilizer hole-applicator via CFD-DEM coupling. Transactions of the CSAE, 2019; 35(21): 18-25. (in Chinese)

[19] Li Z Q, Chen L Q, Zheng Q, Dou X Y, Yang L. Control of a path following caterpillar robot based on a sliding mode variable structure algorithm. Biosystems Engineering, 2019, 186: 293-306.

[20] Wang Y B, Rong G, Li H W, Wang Q J, He J, Lu C Y. Design and parameter optimization of vertical driving-type surface rotary tillage machine. Transactions of the CSAE, 2019; 35(9): 38-47. (in Chinese)

[21] Zhao Z, Huang H D, Yin J J, Simon X. Dynamic analysis and reliability design of round baler feeding device for rice straw harvest. Biosystems Engineering, 2018; 174: 10-19.

[22] Wang W W, Zhu C X, Chen L Q, Li Z D, Huang X, Li J C. Design and experiment of active straw-removing anti-blocking device for maize no-tillage planter. Transactions of the CSAE, 2017; 33(24): 10-17. (in Chinese)

[23] Lei X L, Liao Y T, Liao Q X. Simulation of seed motion in seed feeding device with DEM-CFD coupling approach for rapeseed and wheat. Computers and Electronics in Agriculture, 2016; 131: 29-39.

[24] Ma Z, Li Y M, Xu L Z. Discrete-element method simulation of agricultural particles' motion in variable-amplitude screen box. Computers and Electronics in Agriculture, 2015; 118: 92-99.

[25] Su Y L, Hou X Y, Li L, Cao G Y, Chen X L, Jin T, et al. Study on impact energy absorption and adhesion of biomimetic buffer system for space robots. Advances in Space Research, 2020; 65(5): 1353-1366.

[26] Cundall P, Strack O. A discrete numerical model for granular assemblies. Geotechnique, 1979; 29(1): 47-65.

[27] Renzo A D, Maio F P D. Comparison of contact-force models for the simulation of collisions in DEM-based granular flow codes. Chem. Eng. Sci., 2004; 59(3): 525-541.

[28] Zhang Z, Jia X H, Yang T, Gu Y L, Wang W W, Chen L Q Multi-objective optimization of lubricant volume in an ELSD considering thermal effects. International Journal of Thermal Sciences, 2021; 164(5): 106884. doi: 10.1016/j.ijthermalsci.2021.106884.

[29] Chen L Q, Ma P P, Tian J L, Liang X T. Prediction and optimization of lubrication performance for a transfer case based on computational fluid dynamics. Engineering Applications of Computational Fluid Mechanics, 2019; 13(1): 1013-1023. 